
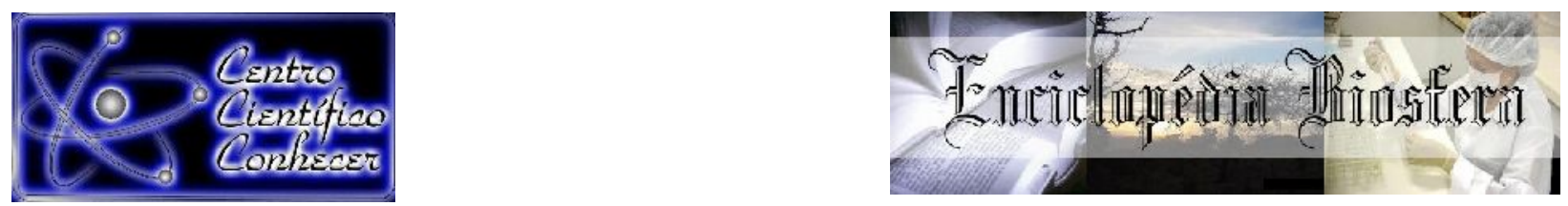

\title{
ASPECTOS MORFOFUNCIONAIS DA CAVIDADE BUCOFARINGIANA DE Australoheros cf. facetus (PERCIFORMES, CICHLIDAE)
}

\author{
Jeane Campos Silva ${ }^{1}$, Cláudia Maria Reis Raposo Maciel ${ }^{2}$, \\ Leonilde Xavier Costa ${ }^{3}$, Lidiane da Silva Nascimento ${ }^{4}$, Alaor Maciel Júnior ${ }^{2}$ \\ ${ }^{1}$ Discente do curso de Ciências Biológicas da UESB, Itapetinga, BA. \\ Email: jeane_campos_silva@hotmail.com \\ 2 Professor Pleno da Universidade Estadual do Sudoeste da Bahia/UESB, \\ Pesquisador do Núcleo de Estudos de Organismos Aquáticos (NEOAQUA), \\ Itapetinga, BA. \\ ${ }^{3}$ Discente do curso de Zootecnia da Universidade Estadual do \\ Sudoeste da Bahia / UESB, Itapetinga, BA. \\ ${ }^{4}$ Bióloga e Doutora em Biologia Celular e Estrutural, Pesquisadora do \\ NEOAQUA/UESB
}

\section{Recebido em: 06/04/2018 - Aprovado em: 10/06/2018 - Publicado em: 20/06/2018} DOI: 10.18677/EnciBio_2018A85

\begin{abstract}
RESUMO
O estudo morfológico da cavidade bucofaringiana é ferramenta importante no fornecimento de informações sobre relações ecológicas tróficas dos peixes diante de alterações das condições ambientais e do alimento disponível. Neste estudo, objetivou-se descrever a morfologia funcional da cavidade bucofaringiana de Australoheros cf. facetus (Perciformes, Cichlidae), com a finalidade de fornecer informações dos aspectos e adaptações morfológicas envolvidos na obtenção do alimento, contribuindo para o conhecimento da biologia da espécie e visando, deste modo, a preservação da espécie e o manejo em cativeiro. Utilizou-se 14 exemplares de Australoheros cf. facetus coletados no rio Catolé Grande, Bahia. Cortes anatômicos e diafanização de peças foram realizados e as peças anatômicas foram analisadas com auxílio do microscópio estereoscópico. A boca de $A$. cf. facetus é protrátil e a abertura oral possui formato tubular, sendo levemente convexa quando fechada. Os dentes orais, mandibulares e pré-maxilares são funcionais. $O$ assoalho, constituído pela língua e pelos músculos intermandibulares, não possui pregas relevantes, e a mucosa do teto possui pregas longitudinais onduladas paralelas entre si, com sulcos entre elas. As adaptações morfofuncionais verificadas na cavidade bucofaringiana de $A$. cf. facetus são condizentes com o hábito alimentar onívoro.
\end{abstract}

PALAVRAS- CHAVE: Anatomia, Boca, Peixes 


\title{
MORPHOFUNCTIONAL ASPECTS OF THE BUCOPHARYNGEAL CAVITY OF Australoheros cf. facetus (PERCIFORMES, CICHLIDAE)
}

\begin{abstract}
The morphological study of the bucopharyngeal cavity is an important tool in providing information on trophic ecological relationships of fishes in face of changes in environmental conditions and the available food. In this study, the objective was to describe the functional morphology of the bucopharyngeal cavity of Australoheros cf. facetus (Perciformes, Cichlidae), in order to provide information on the aspects and morphological adaptations involved in the food obtaining, contributing to the knowledge of the biology of the species, aiming, in this way, its preservation and the handling in captivity. It was used 14 specimens of Australoheros cf. facetus collected in the Catolé Grande river, Bahia. Anatomical cuts and diaphanization of pieces were performed and the anatomical pieces were analyzed at the stereoscopic microscope. The mouth of $A$. cf. facetus is protractile and the oral opening has a tubular shape, slightly convex when closed. The oral, mandibular and premaxillary teeth are functional. The floor, consisting of tongue and the intermandibular muscles, has no relevant folds, and the roof mucosa has corrugated longitudinal parallel folds, with grooves between them. The morphofunctional adaptations observed in the bucopharyngeal cavity of $A$. cf. facetus are consistent with the omnivore feeding habit.
\end{abstract}

KEYWORDS: Anatomy, Mouth, Fish

\section{INTRODUÇÃO}

A cavidade bucofaringiana ou intestino cefálico de peixes apresenta uma série de estruturas importantes na seleção, apreensão e orientação de alimentos para o esôfago (ABBATE et al., 2012; SANTOS et al., 2015). A sua análise é importante para o manejo na piscicultura, uma vez que fornece dados referentes à preferência alimentar das diferentes espécies. Contudo, poucos estudos sobre as adaptações na cavidade bucofaringiana de peixes de água doce foram realizados (RODRIGUES; MENIN, 2006; MACIEL et al., 2009; SCHUINGUES et al., 2013).

As adaptações na cavidade oral podem ser analisadas com base na forma, posição e tamanho da boca, amplitude da fenda oral, forma da rima oral, presença de barbilhões, estrutura dos lábios, língua, presença de valvas orais, dentes orais e faríngeos, presença de rastros branquiais, dentre outras estruturas (RODRIGUES; MENIN, 2006; KALHORO et al., 2017).

A família Cichlidae é a segunda maior dentre os Perciformes e compreende cerca de 1900 espécies no mundo, sendo que, aproximadamente, 450 ocorrem na América do Sul. São peixes de médio porte, atingindo $17 \mathrm{~cm}$ de comprimento. Tem hábito alimentar onívoro, ingerindo detritos e material vegetal, predando pequenos animais aquáticos, incluindo pequenos peixes (FROESE; PAULY, 2017). Dentre as espécies de Cichlidae descritas, encontra-se a Australoheros cf. facetus, nativa da bacia do rio Doce, sendo encontrada também em outras bacias brasileiras (RíCAN; KULLANDER, 2008). A espécie foi também registrada no rio Catolé Grande no munícipio de Itapetinga, Bahia, por Pinto (2013).

Australoheros cf. facetus difere de $A$. facetus (Jenyns 1842) e de outras espécies do mesmo gênero por possuir sete espinhos na nadadeira anal, quatro listras abdominais completamente separadas, comprimento do pedúnculo caudal acima de $48 \%$ da sua largura, e coloração amarelada. Já a espécie $A$. facetus 
(Jenyns 1842) possui seis espinhos na nadadeira anal, com cerca de $80 \%$ dos exemplares com quatro listras abdominais, sendo que em $80-90 \%$ essas listras são incompletas na porção dorsal, comprimento do pedúnculo caudal abaixo de $40 \%$ da largura, cor cinza (RíCAN; KULLANDER, 2008).

É importante salientar que o estudo morfológico, em particular da cavidade bucofaringeana, é uma ferramenta útil no fornecimento de informações sobre relações ecológicas tróficas dos peixes diante de alterações ambientais e da disponibilidade de alimento. Neste estudo, objetivou-se descrever a cavidade bucofaringiana de Australoheros cf. facetus com a finalidade de fornecer informações sobre os aspectos morfológicos envolvidos na obtenção do alimento, facilitando, deste modo, a preservação da espécie e o manejo em cativeiro.

\section{MATERIAL E MÉTODOS}

Este estudo foi realizado de acordo com Princípios Éticos para o Uso de Animais de Laboratório, publicado pelo Colégio Brasileiro de Experimentação Animal - COBEA. As coletas dos exemplares foram realizadas com a autorização do Instituto Chico Mendes de Conservação da Biodiversidade - ICMBio, $n^{\circ} 52380-1$, e o projeto foi submetido e aprovado pela Comissão de Ética no Uso de Animais da Universidade Estadual do Sudoeste da Bahia - CEUA/UESB, protocolo nº 129/2016.

Os exemplares foram coletados no rio Catolé Grande, na região urbana do município de Itapetinga, BA, com auxílio de redes de arrasto e arremesso. Posteriormente, foram encaminhados para o Laboratório de Biologia da Universidade Estadual do Sudoeste da Bahia (UESB), onde procedeu-se a anestesia por imersão em solução de benzocaína $10 \%$, e a fixação em solução aquosa de formol $10 \%$. Todos os exemplares encontram-se armazenados na coleção do referido laboratório, em solução de álcool etílico $70 \%$. Foram utilizados 14 exemplares adultos, machos e fêmeas, de Australoheros cf. facetus (Figura 1), com 7,22 $\pm 2,4 \mathrm{~cm}$ de comprimento-padrão e comprimento médio da cabeça de 2,46 $\pm 0,9 \mathrm{~cm}$.

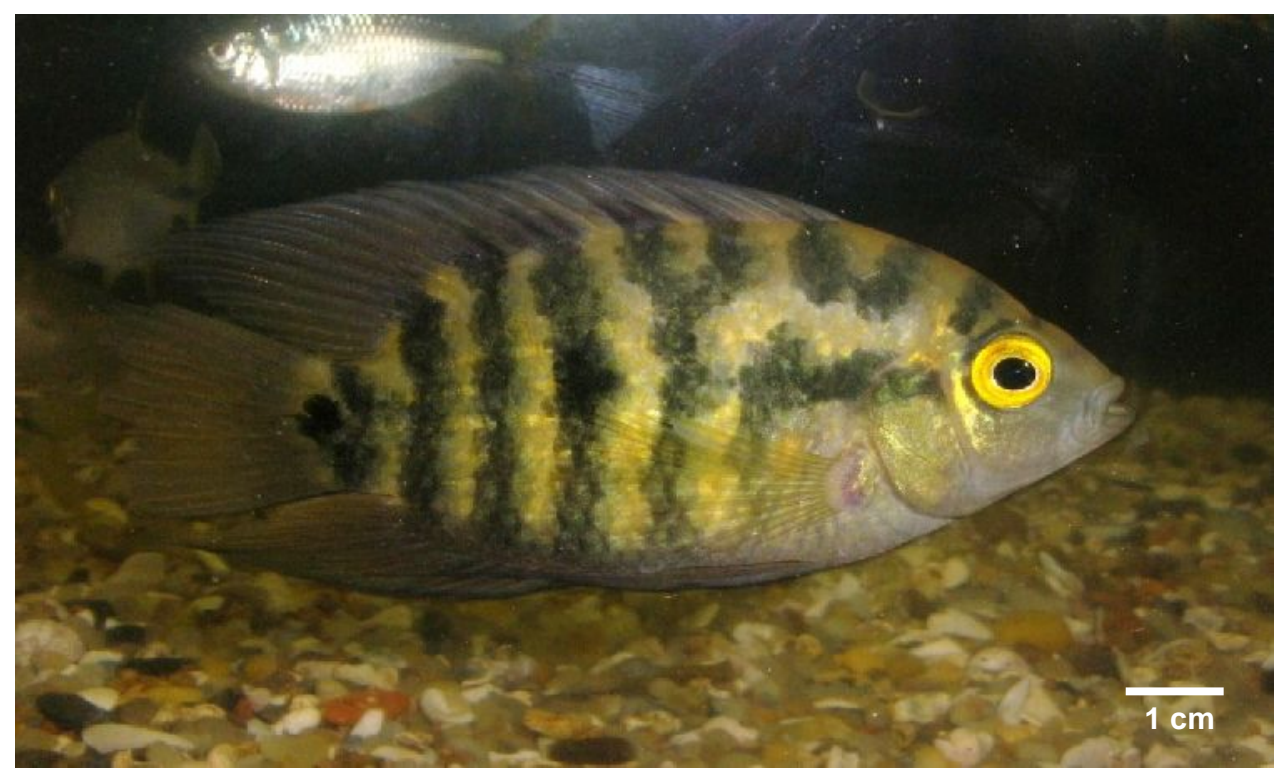

FIGURA 1. Exemplar de Australoheros cf. facetus, coletado no rio Catolé Grande, BA, em 2016. (Fonte: Acervo do Laboratório de Biologia da UESB.). 
A biometria dos exemplares foi realizada com auxílio de paquímetro digital, com precisão de $0,01 \mathrm{~mm}$ e as fotografias com SONY, modelo DSC-H10. As descrições morfológicas foram realizadas com 0 auxílio de microscópio estereoscópico, com aumento de 10 a 40 vezes.

Para descrição da cavidade bucofaringiana foram realizados cortes no plano longitudinal mediano e sagital mediano, sendo analisados os lábios superiores e inferiores, posição da boca e a amplitude da fenda bucal, a orientação, o tipo e disposição de dentes, a língua, o aparelho branquial faringiano, rastros branquiais e o aparelho dentário faringiano. Além disto, dois exemplares foram diafanizados e corados com alizarina e alcian blue (RODRIGUES; MENIN, 2006).

\section{RESULTADOS E DISCUSSÃO}

\section{Lábios}

Os lábios de Australoheros cf. facetus são pigmentados por melanóforos, sendo esses menores e mais aglomerados quando comparados aos da língua. Verificou-se também dentículos labiais com formatos cônicos, voltados para o exterior. Os dentículos labiais estão associados com a capacidade de distensão dos lábios e tem importante função na captura do alimento, permitindo a raspagem e sucção (SILVANO et al., 2001).
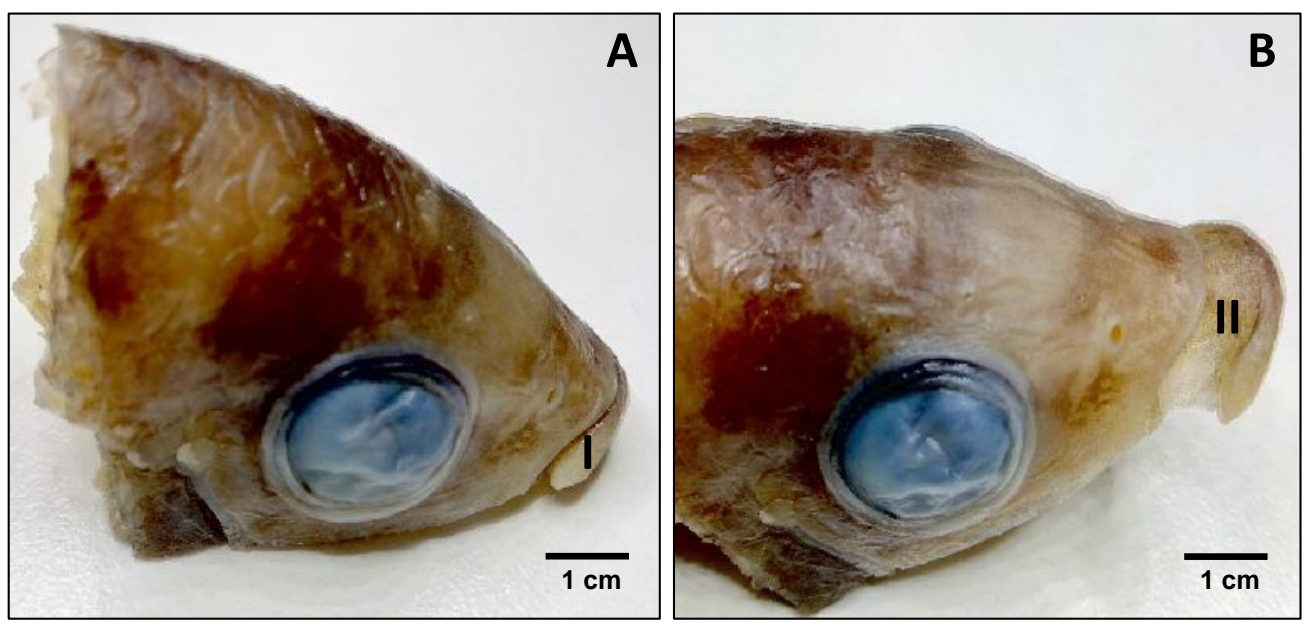

FIGURA 2. Vista dorsal da cabeça de Australoheros cf. facetus. A) Lábio em repouso (I); B) Lábio distendido (II). (Fonte: Autores).

Os lábios superior e inferior são corpulentos e aderidos, respectivamente, à maxila e a mandíbula. O superior é menos espesso e mais recuado com a boca fechada e em repouso, quando comparado com o inferior, no entanto, têm a capacidade de se distender, permitindo que ambos fiquem em posições paralelas na prática de sugar o alimento (Figura 2). 


\section{Boca e cavidade oral}

A boca de Australoheros cf. facetus é terminal, protrátil e pequena. Em vista anterior rostral, a abertura oral tem formato tubular, ao fechar é levemente convexa ventralmente. Em vista lateral a boca é encurvada com concavidade voltada para baixo. Em secção sagital mediana, a cavidade bucofaringiana é tubular e dilatada, e estende-se dos lábios até áreas dentígeras faringianas (Figura 3).

A posição terminal e a protratibilidade da boca são características importantes para a captura do alimento, uma vez que permite a espécie empregar o ato de sucção (Rodrigues e Bemvenuti, 2001). No plano sagital mediano, a cavidade oral é retilínea, ampla e contínua com a cavidade faringiana, que juntas formam a cavidade bucofaringiana (Figuras 3 e 4).

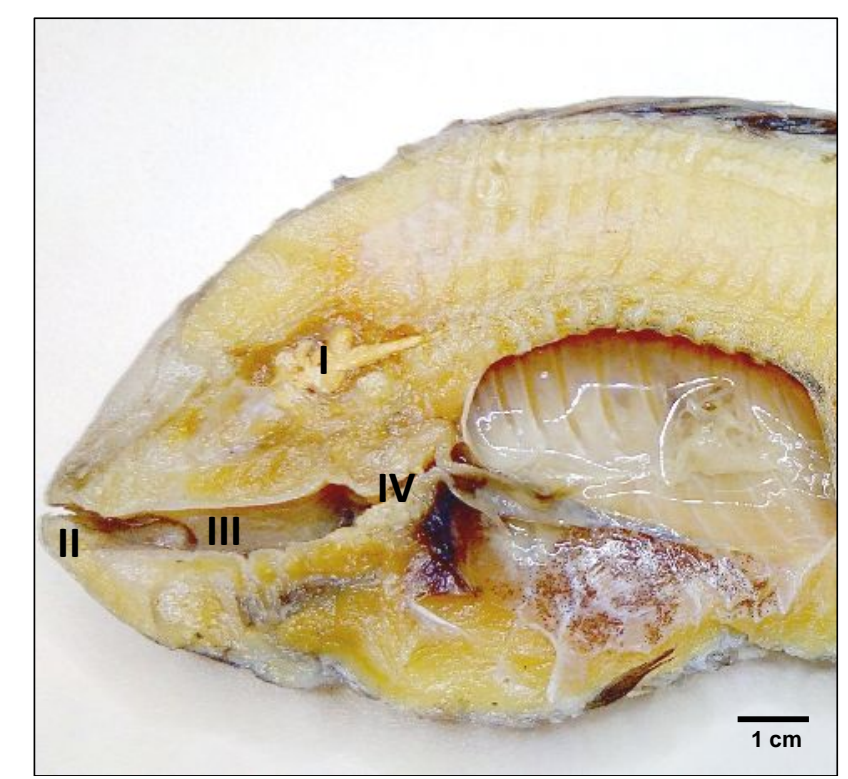

FIGURA 3. Plano sagital mediano, vista lateral direita, de Australoheros cf. facetus do rio Catolé Grande, BA. Encéfalo (I), Lábios (II), Cavidade bucofaringiana (III), Área dentígeras (IV). (Fonte: Autores).

\section{Assoalho e teto da cavidade oral}

O assoalho da cavidade oral de Australoheros cf. facetus é constituído pela língua e pelos músculos intermandibulares, e a mucosa é lisa (Figura 4B), já a mucosa do teto da espécie apresentou pregas longitudinais onduladas paralelas entre si, e a presença de sulcos entre as pregas (Figura 4A). $\mathrm{O}$ fato da mucosa do assoalho não apresentar pregas e a mucosa do teto ter pregas longitudinais permite que o alimento entre sem barreiras com rápida condução para o esôfago, liberando a cavidade bucal (RODRIGUES; MENIN, 2006). 

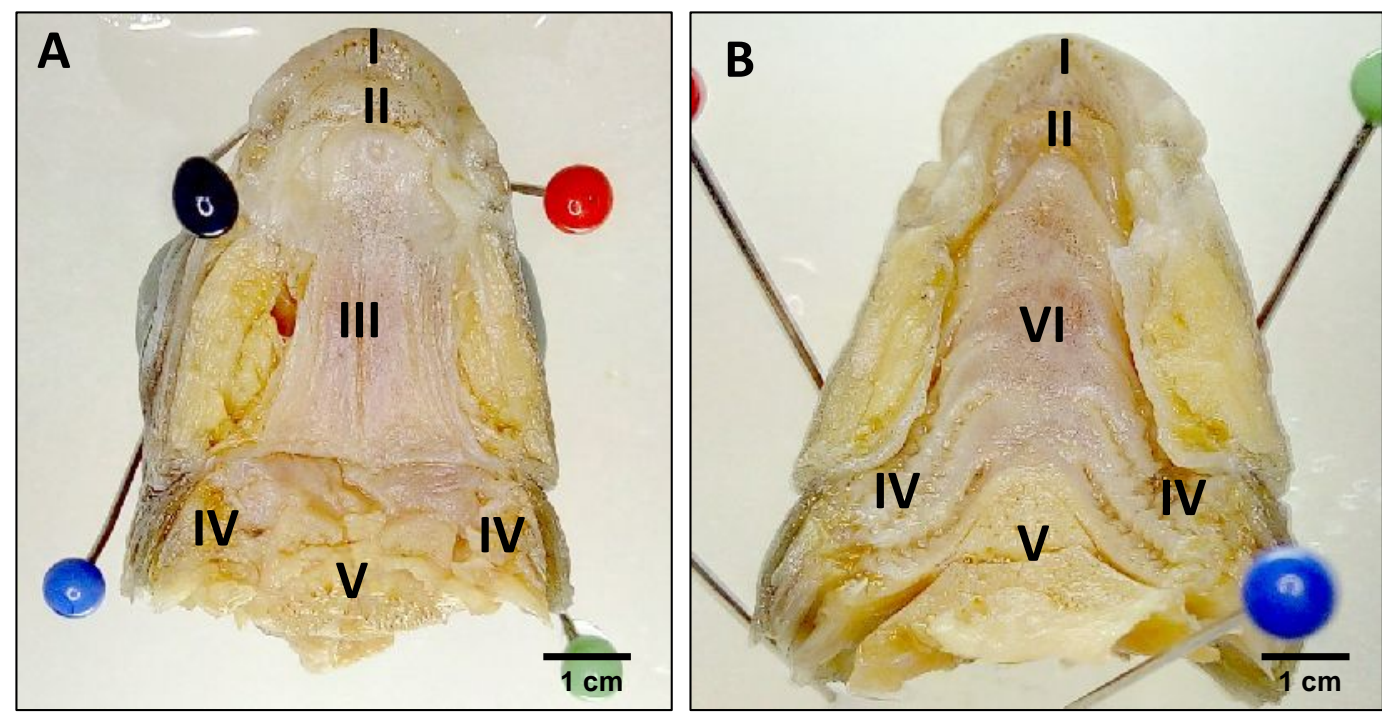

FIGURA 4. Plano longitudinal da cavidade bucofaringiana de Australoheros cf. facetus. A) Teto e B) Assoalho. Sendo: Série de dentes orais (I), Valva oral (II); 3) Teto da cavidade oral (III); Arcos branquiais (IV); Áreas dentígeras faringianas (V); Língua (VI). (Fonte: Autores.).

\section{Língua}

A língua situa-se em uma concavidade do assoalho da cavidade oral (Figura $5 A$ ), sendo pouco presa e com pouca mobilidade. Alarga-se em sentido caudal, apresentando elevações evidentes, não há dentículos ou placas dentígeras. A língua em peixes não participa do processo de deglutição, contudo, a presença de botões gustativos sugere funções mecânicas e sensoriais (ABBATE et al., 2012; SANTOS et al., 2015). Pigmentação de língua é uma característica comum em peixes (NAZAROV et al., 2013), na espécie em estudo, observa-se a presença expressiva de melanóforos dendríticos em toda sua extensão (Figura 5B).

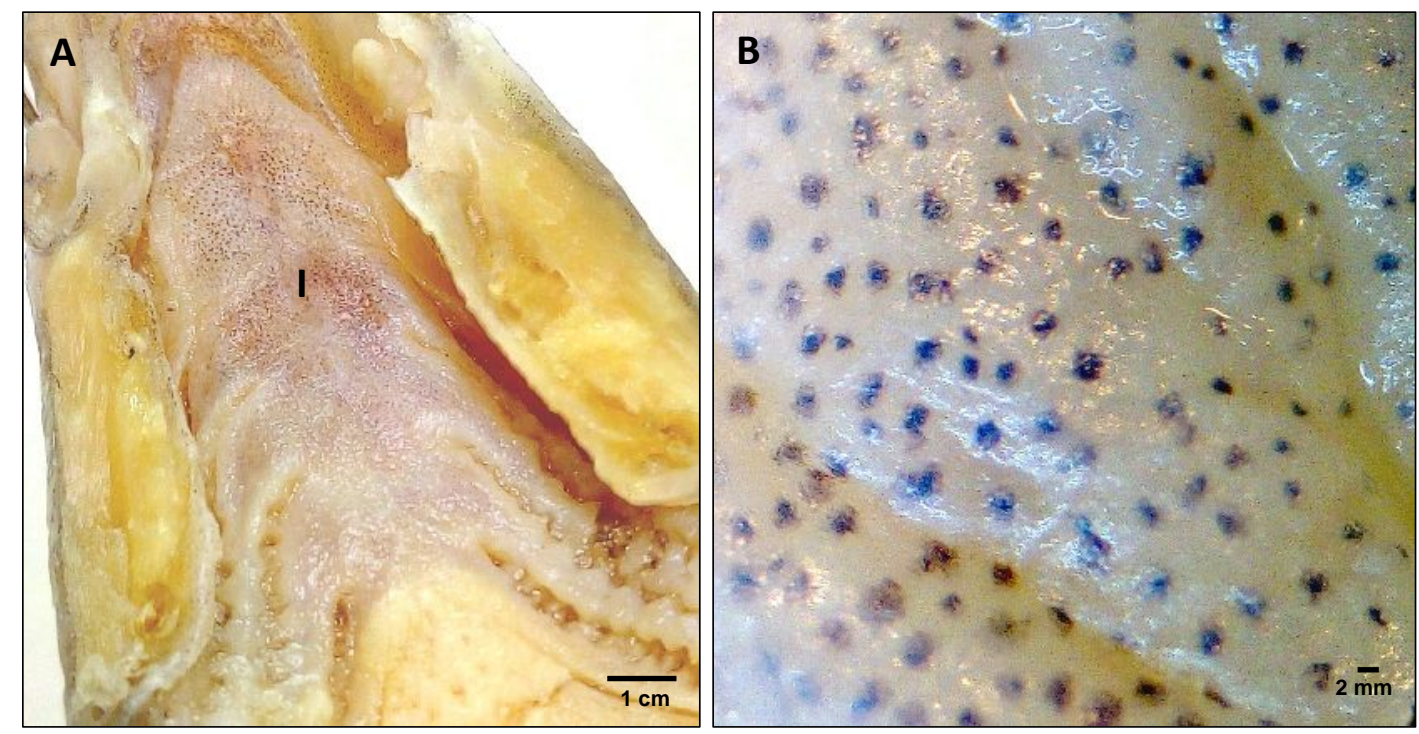

FIGURA 5. Plano longitudinal do assoalho da cavidade bucofaringiana de Australoheros cf. facetus, evidenciando a língua (A) e a pigmentação com melanóforos (B). (Fonte: Autores.). 


\section{Dentição oral}

Australoheros cf. facetus apresenta dentes orais mandibulares e prémaxilares funcionais (Figura 4) envolvidos na apreensão e retenção do alimento. Os dentes orais pré-maxilares funcionais estão distribuídos em duas séries contínuas e regulares de dentes cônicos, sendo a mais externa constituída por dentes grandes orientados para fora, e a interna por dentes pequenos orientados para cavidade bucal e em menor número, quando comparado com a série externa (Figura 6).

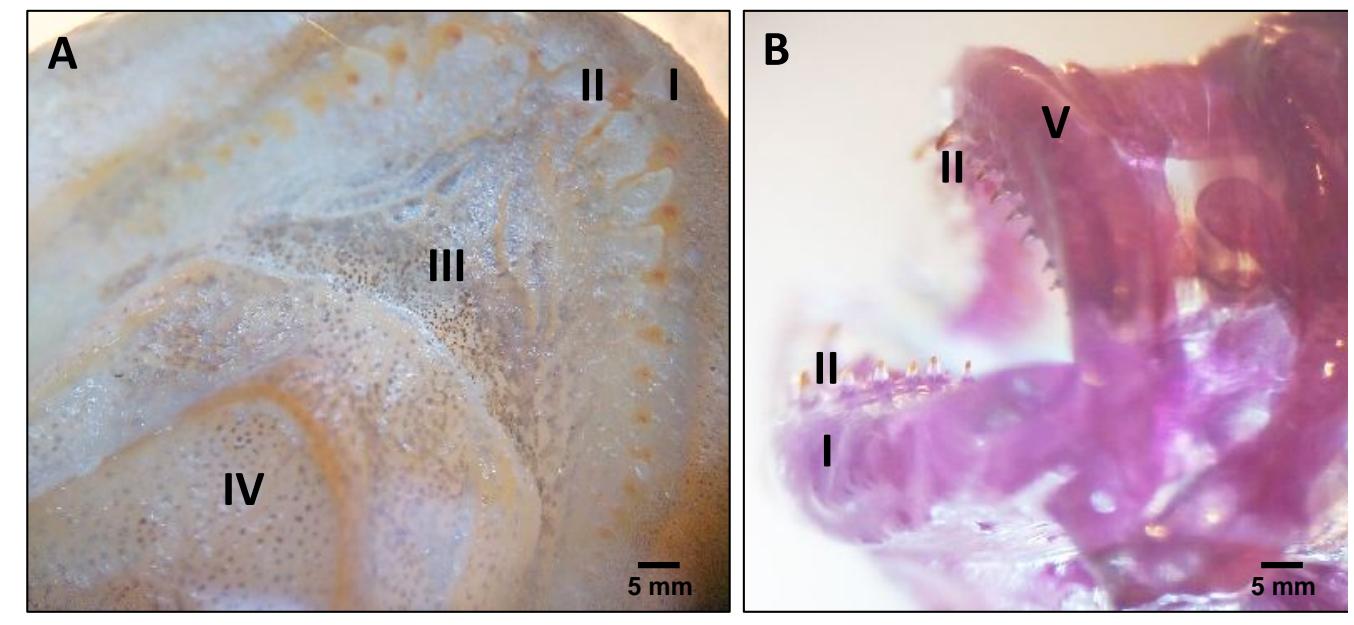

FIGURA 6. Dentes orais de Australoheros cf. facetus. A) Porção anterior do assoalho da cavidade oral; B) Abertura bucal diafanizada e corada com alizarina e alcian blue. Sendo: I) Lábio inferior, mandíbula, II) Dentes orais inferiores, III) Mucosa do assoalho da cavidade oral, IV) Língua, V) Maxila. (Fonte: Autores.).

Os dentes mandibulares estão dispostos em três séries e todos orientados para a cavidade bucal. A primeira série apresenta dentes grandes e numerosos que diminuem de tamanho gradativamente em direção as laterais da cavidade oral (Figura 6). A segunda série possui dentes pequenos parcialmente desenvolvidos e em menor número quando comparado com a primeira, já a terceira série apresenta dentes muito pequenos e pouco desenvolvidos. Quanto à forma e coloração dos dentes, as raízes são brancas e largas em sua base e o ápice, ficam amarelados e pontiagudos à medida que se aproximam da coroa.

Os dentes orais de $A$. cf. facetus são pouco desenvolvidos em comparação com outras espécies onívoras como Leporinus friderici e Leporinus taeniofasciatus, as quais possuem dentes incisivos bem desenvolvidos e de corte acentuado (ALBRECHT et al., 2005). Tal variação tem relação com o desenvolvimento da dentição e os tipos de alimentos (MACIEL et al., 2009; PESSOA et al., 2013).

\section{Valvas orais}

A valva oral superior-maxilar (Figura 7A) é maior e mais desenvolvida que a inferior-mandibular (Figura 7B). Quanto à pigmentação, ambas apresentam melanóforos, sendo a inferior com maior número. Quanto à forma, a valva inferior tem formato triangular e concavidade mais acentuada, enquanto que a superior apresenta forma de um trapézio simétrico. As valvas orais de Australoheros cf. facetus são utilizadas na regulação do fluxo de água (HELFMAN et al., 2009), conforme também descrita para outras espécies (MACIEL et al., 2009). 

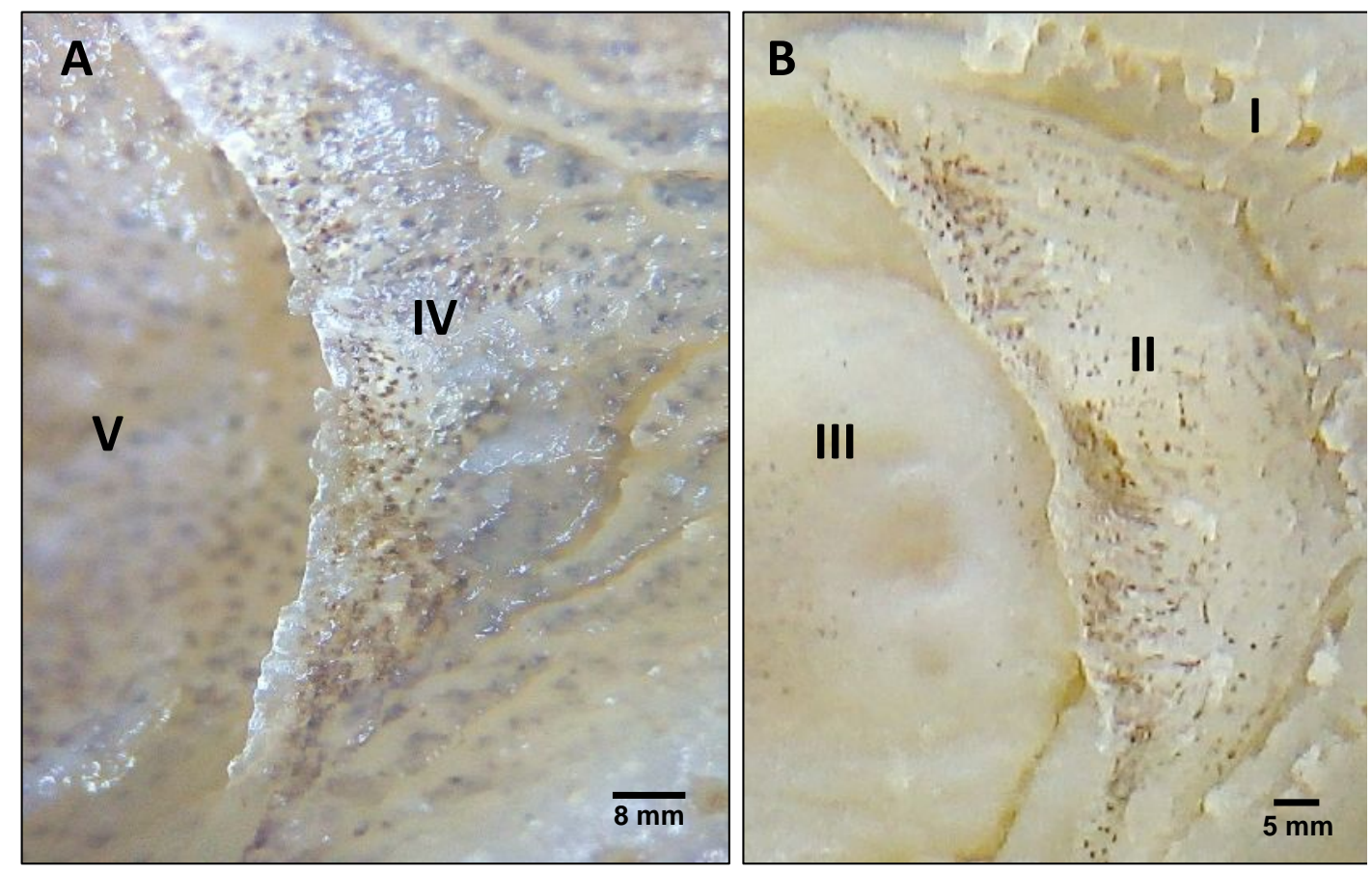

FIGURA 7. Valvas orais de Australoheros cf. facetus. A) Valva oral superior ou maxilar, B) Valva oral inferior ou mandibular. Sendo: Série de dentes orais superiores (I); Valva oral superior (II); Teto da cavidade bucal (III); Valva oral inferior (IV); Língua (V). (Fonte: Autores.).

\section{Faringe}

A faringe têm forma triangular com a base do triângulo voltada para o esôfago e alarga-se em sentido caudal (Figura 4), a mucosa não possui relevos significantes (Figuras 8A). São quatro pares de arcos branquiais I, II, III e IV, que gradativamente diminuem o tamanho (Figura 8B).

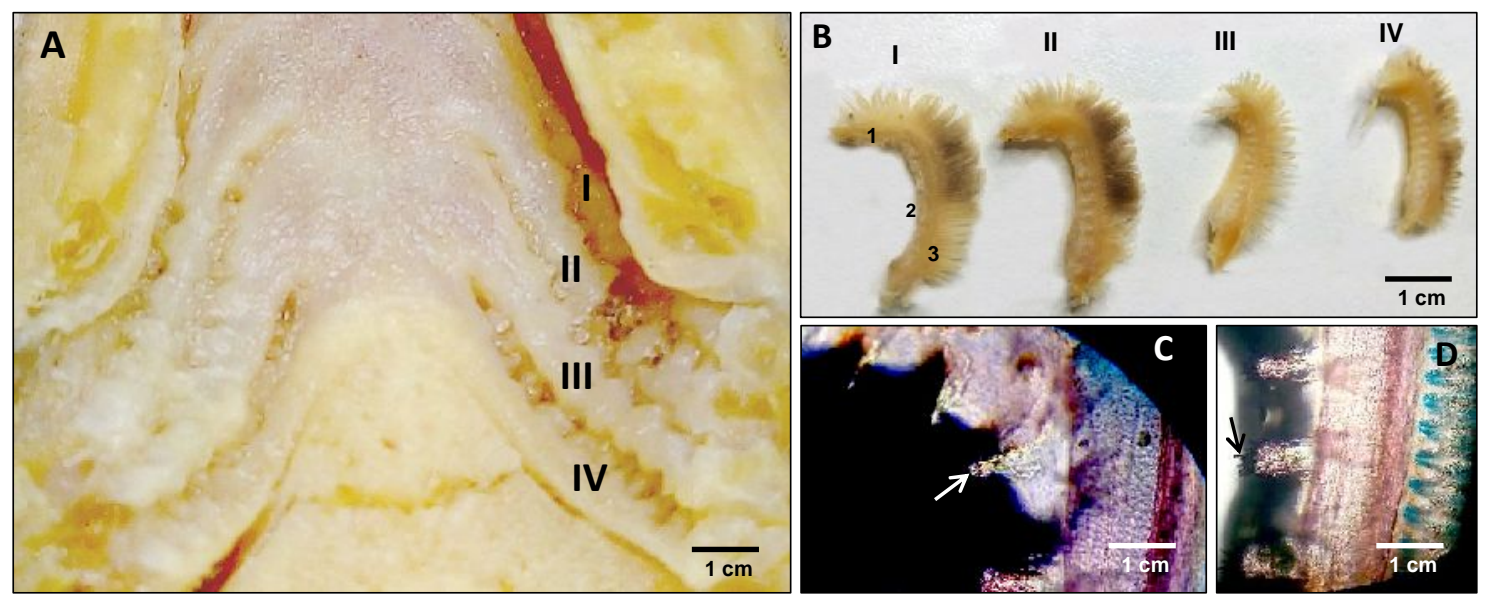

FIGURA 8. Assoalho da faringe de Australoheros cf. facetus. A) Assoalho evidenciando os arcos branquiais e rastros branquiais, B) Arcos branquiais I - IV, C e D) Rastros branquiais na borda anterior do arco branquial - Seta branca: Rastros branquiais, seta preta: dentículos dos rastros branquiais. (Fonte: Autores.). 
Os arcos branquiais I, II, III e IV são formados pelos ramos superiores e inferiores (Figura 8B). O ramo superior é constituído pelos ossos faringobranquial e o epibranquial e o ramo inferior pelos ossos hipobranquial e ceratobranquial. Nos arcos branquiais do I ao III, o ramo superior é formado pelo osso epibranqueal e o ramo inferior pelo osso ceratobranquial.

Rastros branquiais estão presentes nas faces internas e externas dos arcos I, II e III, no arco branquial IV ocorrem rastros somente na face interna, contudo a face externa apresenta dentículos desenvolvidos e pontiagudos (Figura 8C). Nos arcos I e II, os rastros são do tipo triangular e pontiagudos ocorrendo dentículos na coroa da sua estrutura (Figura 8D), mesmo padrão ocorre com os arcos branquiais III e IV. A presença dos filamentos branquiais na borda externa dos quatro arcos branquiais é registrada (Figura $8 \mathrm{~B}$ ).

Diferentemente do formato de rastros branquiais encontrados para $A$. cf. facetus, Albrecht et al. (2005) descreveram os rastros branquiais de duas espécies onívoras, L. friderici e L. taeniofasciatus, como sendo muito grossos, inferindo que os mesmos não teriam papel na captura do alimento. Com base na forma e na presença de dentículos desenvolvidos e pontiagudos da espécie em estudo pode-se inferir que seus rastros branquiais participam da obtenção do alimento. Embora o número, a espessura e a forma dos rastros branquiais variem entre as diferentes espécies de peixes (ELSHEIKH, 2013; PESSOA et al., 2013), estas estruturas estão envolvidas em uma ou mais funções, tais como filtragem, captura do alimento e/ou proteção dos filamentos branquiais.

\section{Dentição faringiana}

Em plano longitudinal mediano, visualizam-se áreas dentígeras faringianas no assoalho e teto faringiano de Australoheros cf. facetus (Figura 4). No teto faringiano são observadas duas áreas dentígeras faringianas constituídas por dentes cônicos, pequenos e grandes, voltados para dentro da cavidade peritoneal, ou seja, em direção ao esôfago (Figura 9A). Os dentes maiores apresentam desgaste natural e diminuem o tamanho gradativamente à medida que se aproximam da cavidade peritoneal. No teto ocorrem ainda duas áreas dentígeras faringobranquiais com dentes menos desenvolvidos e em quantidade relativamente menor quando comparados com a área dentígera faringiana (Figura 9A).
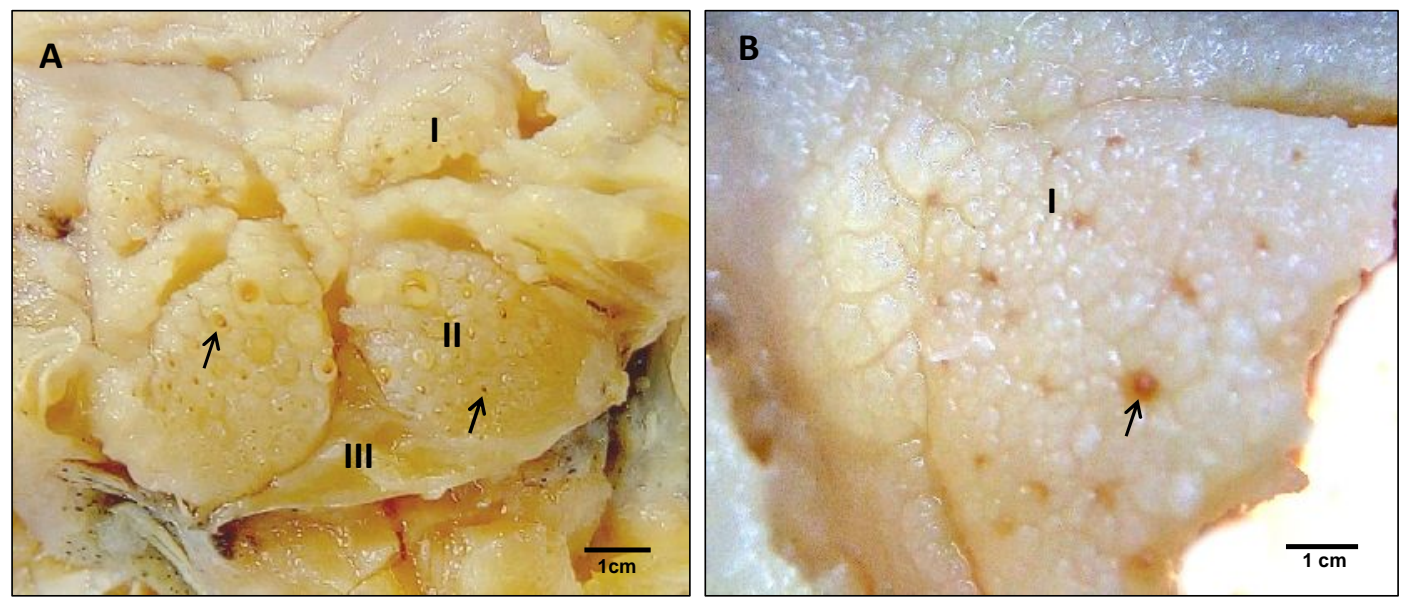

FIGURA 9. Areas dentígeras faringianas de Australoheros cf. facetus. A) Areas dentígeras faringianas superiores; B) Área dentígeras faringianas inferiores. Sendo: I, II e III áreas dentígeras com dentes cônicos (seta preta). (Fonte: Autores.). 
No assoalho faringiano de Australoheros cf. facetus, as áreas dentígeras não estão organizadas em duas placas distintas em semelhança às áreas superiores (Figura 9A). Os dentes cônicos são pontiagudos e estão distribuídos de forma dispersa e dispostos de forma triangular, alargando-se em sentido caudal (Figura 9B).

De modo geral, os dentes faringianos podem estar associados à apreensão, agarramento, imobilização e prevenção do escape de presas pequenas em peixes carnívoros (RODRIGUES ; MENIN, 2006; SCHUINGUES et al., 2013; MAHMOUD et al. 2016) e onívoros (AMORIM-SANTOS, 2015) e na trituração do alimento nos herbívoros e onívoros (ALBRECHT et al., 2005; RODRIGUES et al., 2008). $\mathrm{Na}$ espécie em estudo, a forma e a disposição em sentido aboral dos dentes indicam que estes estão envolvidos com a captura do alimento, como também na trituração de material vegetal.

\section{CONCLUSÃO}

A cavidade bucofaringiana de Australoheros cf. facetus apresentou adaptações condizentes com a prática de captura do alimento, início do processo digestivo e com o hábito alimentar onívoro.

\section{AGRADECIMENTOS}

Ao Conselho Nacional de Pesquisa/CNPq e à Fundação de Amparo e Pesquisa da Bahia/APESB pelas concessões das bolsas de iniciação científica.

\section{REFERÊNCIAS}

ABBATE, F.; GUERRERA, M.C.; MONTALBANO, G.; CIRIACO, E.; GERMANÁ, A. Morphology of the tongue dorsal surface of gilthead seabream (Sparus aurata). Microscopy Research and Technique, v. 75, n. 12, p.1666-1671, 2012. Disponível em:<https://doi.org/10.1002/jemt.22114>. doi: 10.1002/jemt.22114.

ALBRECHT, M. P.; FERREIRA, M. F. N.; CARAMASCHI, E. P. Anatomical features and histology of the digestive tract of two related neotropical omnivorous fishes (Characiformes; Anostomidae). Journal of Fish Biology, v. 58, n. 2, p. 419-430, 2005. Disponível em:< https://doi.org/10.1111/j.1095-8649.2001.tb02261.x>. doi: 10.1111/j.1095-8649.2001.tb02261.x.

AMORIM-SANTOS, T. Ciclídeos no rio Catolé Grande no trecho urbano de Itapetinga, BA: Ecomorfologia e alimentação. Dissertação (Mestrado em Ciências Ambientais) - Universidade Estadual do Sudoeste da Bahia, Itapetinga, 2015. 57p. Disponível em:< http://www.uesb.br/ppgca/dissertacoes/2015/DISSERTACAO-TalitaAmorim.pdf $>$.Acesso em: jan, 2018.

ELSHEIKH, E.H. Scanning electron microscopic studies of gill arches and rakers in relation to feeding habits of some fresh water fishes. The Journal of Basic \& Applied Zoology, v. 66, n. 3, p. 121-130, 2013. Disponível em:< https://doi.org/10.1016/j.jobaz.2013.07.005>. doi: 10.1016/j.jobaz.2013.07.005. 
FROESE, R.; PAULY, D. editors. Australoheros facetus (Jenyns, 1842). FishBase. Disponível em: <http://www.fishbase.se/summary/Australoheros-facetus.html>. Acesso em: jan, 2018.

HELFMAN, G. S.; COLLETTE, B.B.; FACEY, D. E.; BOWEN, B. W. The diversity of fishes: Biology, Evolution, and Ecology. West Sussex, Wiley-Blackwell, $2^{a}$ edição, 720 p, 2009.

KALHORO, H.;TONG, S.; WANG, L.; HUA, Y.; VOLATIANA, J.A.; SHAO, Q. Gross anatomical and histomorphological features of the Acanthopagrus schlegelii digestive tract (Bleeker 1854) Perciformes, Sparidae. Acta Zoologica, v. 00, p. 1-12, 2017. Disponível em: <https://doi.org/10.1111/azo.12225>. doi: 10.1111/azo.12225.

MACIEL, C.M.R.R.; JÚNIOR, A.M.; LANNA, E.A.T.; MENIN, E. Anatomia funcional da cavidade bucofaringiana de trairão, Hoplias lacerdae Miranda Ribeiro, 1908 (Characiformes, Erythrinidae). Revista Biotemas, v. 22, n.3, p. 95-102, 2009. Disponível em:< https://doi.org/10.5007/2175-7925.2009v22n3p95>. doi: 10.5007 /2175-7925.2009v22n3p95.

MAHMOUD, U. M.; ESSA, F.; SAYED, A. E. Surface architecture of the oropharyngeal cavity and the digestive tract of Mulloidichthys flavolineatus from the red sea, Egypt: A scanning electron microscope study. Tissue and Cell, v. 48, n. 6, p. 624-633, 2016. Disponível em:< https://doi.org/10.1016/j.tice.2016.09.001>. doi: 10.1016/j.tice.2016.09.001.

NAZAROV, D.Y.; KUCHERYAVYY, A. V.; PAVLOV, D. S. Structure and Pigmentation of Tongue Precursor of Larval Arctic Lamprey Lethenteron camtschaticum (Petromyzontiformes, Petromyzontidae) from Rivers of the Russian Far East. Journal of Ichthyology, v. 53, n. 11, p. 959-968, 2013. Disponível em:< http://dx.doi.org/10.1134/S0032945213110076>. doi: 10.1134/S0032945213110076.

PESSOA, E. K. R.; SILVA, N. B.; CHELLAPPA, N. T.; SOUZA, A. A. ; CHELLAPPA, S. Morfologia comparativa do trato digestório dos peixes Hoplias malabaricus e Hypostomus pusarum do açude Marechal Dutra, Rio Grande do Norte, Brasil. Biota Amazônia, v.3, n.1, p.48-57, 2013. Disponível em: < http://dx.doi.org/10.18561/21795746/biotaamazonia.v3n1p48-57>.doi:10.18561/2179-5746/biotaamazonia.v3n1p4857.

PINTO, R.C.A.B.L. Caracterização da ictiofauna do rio Catolé Grande, no município de Itapetinga-BA. Dissertação (Mestrado em Ciências Ambientais) Universidade Estadual do Sudoeste da Bahia, Itapetinga, Ba, 2013, 69p. Disponível em:< http://www.uesb.br/ppgca/dissertacoes/2013/Rita-Pinto.pdf>. Acesso em: jan, 2018.

RÍCAN, O.; KULLANDER, S. O. The Australoheros (Teleostei: Cichlidae) species of the Uruguay and Paraná River drainages. Zootaxa, v. 1724, p. 1-51, 2008. Disponível em: <http://www.mapress.com/j/zt/article/view/4599. Acesso em: fev, 2018. 
RODRIGUES, F. L.; BEMVENUTI, M. A. Hábito alimentar e osteologia da boca do peixe-rei, Odontesthes humensis de Buen (Atheriniformes, Atherinopsidae) na Lagoa Mirim, Rio Grande do Sul, Brasil. Revista Brasileira de Zoologia, v. 18, n. 3, p. 793802, 2001. Disponível em: < http://dx.doi.org/10.1590/S0101-81752001000300015. >.doi:10.1590/S0101-81752001000300015.

RODRIGUES, S. S.; MENIN, E. Adaptações anatômicas da cavidade bucofaringiana de Pseudoplatystoma corruscans (SPIX E AGASSIZ, 1829) (SILURIFORMES, PIMELODIDAE) em relação ao seu hábito alimentar. Revista Ceres, v. 53, n. 305, p. 135-146, 2006. Disponível em: < http://www.ceres.ufv.br/ojs/index.php/ceres/artic le/view/3121/1014. Acesso em: jan, 2018.

RODRIGUES, S. S.; NAVARRO, R. D.; MENIN, E. Adaptações anatômicas da cavidade bucofaringiana de Leporinus macrocephalus Garavello e Britski, 1988 (Characiformes, Anostomidae) em relação ao hábito alimentar. Revista Biotemas, v. 19, n. 1, p. 51-58, 2008. Disponível em:< https://doi.org/10.5007/\%25x>. doi: $10.5007 / \% 25 x$.

SANTOS, M. L.; ARANTES, F. P.; PESSALI, T. C.; SANTOS, J. E. Morphological, histological and histochemical analysis of the digestive tract of Trachelyopterus striatulus (Siluriformes: Auchenipteridae). Zoologia, v. 32, n.4, p. 296-305, 2015. Disponível em:< http://dx.doi.org/10.1590/S1984-46702015000400005>. doi: 10.1590/S1984-46702015000400005.

SCHUINGUES. C. O.; LIMA M. G.; LIMA. R. A.; MARTINS. D. S.; COSTA, G. M. Anatomia da cavidade bucofaringeana de Sorubim trigonocephalus (Siluriformes, Osteichthyes). Pesquisa Veterinária Brasileira, v. 33, n.10, p. 1256-1262, 2013. Disponível em:< https://dx.doi.org/10.1590/S0100-736X2013001000011>. doi: 10.1590/S0100-736X2013001000011

SILVANO, R.; OYAKAWA, O.; AMARAL, B.; BEGOSSI, A. Peixes do alto rio Juruá (Amazonas, Brasil). São Paulo: EDUSP, 2001, 302 p. 